\title{
JANO: EL DIOS DE LOS INICIOS Y EL DIOS DE LAS PUERTAS
}

\author{
Kattia Chinchilla Sánchez
}

\begin{abstract}
RESUMEN
Jano era un dios autóctono de Roma. Entre sus atributos se encontraban la puerta (y el acceso), la llave y el inicio. Estos atributos se relacionan en el doble rostro de Jano que evidencia la doble naturaleza de cada uno: de la puerta (adentro/afuera), de la llave (abierto/cerrado) y del comienzo (inicio/final). Con su doble cara, Jano podía ver el futuro y el pasado. La guerra y la paz, de naturalezas opuestas, se relacionan con Jano: su templo permanecía abierto en tiempo de guerra y cerrado en tiempu le paz.
\end{abstract}

\begin{abstract}
Janus was an ancient and an autochtonus god of Rome. Among his attributes was the door (and all access), the key, the beginning. All of these caractheristics are similar because the double face of Janus indicates the double nature of the door (in/out), the key (open/close) and the beginning (begin/end). Then the god can see the future and the past with his double face. The peace and the war, opposites in nature, are related to the god: his temple was open in war and close in peace.
\end{abstract}

\section{Introducción}

Popular y ancestral en la romanidad, las dos caras, una que mira hacia adelante y otra hacia atrás, son las características más notorias en Jano, divinidad propia, exclusiva de Roma, donde habría reinado con Cameses, un rey mítico del cual apenas si tenemos noticia. En este sentido, ciertos mitógrafos opinan que Jano era un dios extranjero, venido de Tesalia; desterrado de Roma, Cameses lo habría acogido hasta el punto de compartir el poder. Jano erigió una ciudadela en la cima de una colina, la cual tomará desde entonces el nombre de Janículo.

Pasaba por ser una de las deidades romanas más antiguas: su culto habría sido introducido por el propio Rómulo, su nombre figura en los cantos rituales de los salios, sacerdotes instituidos por Numa Pompilio y el santuario, que le estaba consagrado en el Foro, no había perdido aún su importancia en el cuarto siglo de la era cristiana. No se encuentran rasgos similares a él ni en Grecia, ni en Oriente ni en ninguna otra religión de la Antigüedad, por lo cual la mayoría de estudiosos concluyen que se trata de un dios particular de Italia. 
Según los pocos relatos acerca de Jano, llegado a Italia casóse con Camise o Camasena y tuvo entre sus hijos a Tíber, epónimo del río. Otros narraban que el dios se desposó con la ninfa Juturna y con ella había tenido al dios Fons o Fontus, deidad de las fuentes.

\section{Etimología}

La etimología del nombre de Jano es incierta e inclusive los mismos antiguos no la conocían con certeza. Algunos, como Nígidio Figulo, relacionan la forma Janus con la forma Jana, a veces empleada en lugar de Diana:

Pronuntiavit Nigidius Apollinem Janum esse Diananque Janam, apposita 'd' littera, quae saepe ' $i$ ' litterae causa decoris apponitur: reditur, redhibetur, redintegratur, et similia.

Nigidio ha dicho expresamente que Apolo y Jano son idénticos, como Diana y Jana; se ha añadido la letra 'd', que se ha adicionado delante a menudo una ' $i$ ' por eufonía, como en reditur, redhibetur, redintegratur y similares (Macrobio I, 9, 8; la traducción es nuestra).

Otros, entre ellos Cicerón, piensan que el origen de la palabra debe ser buscado en el verbo ire:

Asimismo, puesto que el comienzo y el fin son las partes más importantes de todos los asuntos, afirman que Janus o Ianus es el jefe o príncipe en la ofrenda de un sacrificio, procediendo su nombre de ire, ir, de donde también los nombres de iani para designar los arcos de salida de los caminos, y de ianuae para designar las puertas frontales de los edificios profanos (Cicerón II, 27, 67).

Los historiadores y los críticos modernos no están menos vacilantes y menos divididos. Tanto Buttman como Schwegler y Preller se unen a la opinión de Nigidio Figulo y ven en el nombre de Jano la forma masculina, apenas modificada, del binomio femenino Diana-Jana. A este doble nombre Dianus-Diana, le atribuyen una raíz común: dius o dium, cielo luminoso. Crossen y otros autores se inclinan por el radical "div" (dividir, división) y creen que la forma primitiva del nombre Janus o Dianus era Divanus. Siendo así, el dios presidiría las divisiones, los límites del espacio y del tiempo. Roscher, sin embargo, reconoce que no se ha hallado una raíz para el nombre de la deidad, pero admite que, para los nombres comunes janus y јапиа, Cicerón brindó una etimología acertada a partir del verbo ire.

Existe una notoria relación entre Janus y el nombre común janus, esto parece ser el consenso entre los estudiosos. Y realmente, sobre todo en Roma, Jano era el dios de los jani: puertas en forma de arco, bajo las cuales pasan las vías más frecuentes. Eran las puertas públicas.

\section{Epítetos, atributos y tradiciones}

Herodiano lo llama "dios nacional antiquísimo de Italia" ( $\theta \in$ òs ảpxaıo'Tatos Tîs 'I $\tau \alpha$ -

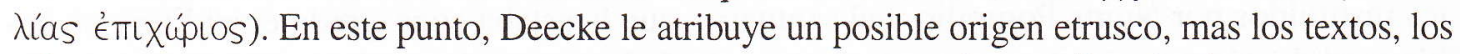
mitos y los monumentos concuerdan para demostrar que Jano fue un dios absolutamente romano. Quirino es uno de sus nombres usuales: 
El templo de Jano Quirino, que solamente había estado cerrado dos veces desde la fundación de Roma, lo estuvo tres entonces; en tiempo mucho más corto, por estar asegurada la paz por mar y tierra (Suetonio, Augusto, 22). Clusivio:

Igualmente, ostentaba los apelativos Gemino, Pater, Junonio, Consivio, Patulcio y

In sacris quoque invocamus Janum Geminum, Janum Patrem, Janum Junonium, Janum Consivium, Janum Quirinum, Janum Patultium et Janum Clusivium. Cur Geminum invocemus supra iam diximus, Patrem quasi deorum deum; Junonium quasi non solum mensis Januarii, sed mensium omnium ingressus tenetem; in dictione autem Junonis sunt omnes kalendae, unde et Varro, libro quinto Rerum divinarum scribit Jano duodecim aras pro totidem mensibus dedicatas; Consivium a conserendo, id est a propagine generis humani, quae Jano auctore conseritur; Quirinum, quasi bellorum potetem ab hasta, quam Sabini corin vocant; Patultium et Clusivium, quia bello caulae eius patent, pace clauduntur. Hius autem rei haec causa narratur.

Igualmente, en los sacrificios nosotros lo invocamos bajo los nombres de Jano Gemino, Jano Pater, Jano Junonio, Jano Consivio, Jano Quirino, Jano Patulcio y Clusivio. ¿Por qué bajo este nombre de Gemino?, yo ya lo he dicho arriba; Pater, como dios de dioses; Junonio, porque él guarda la entrada, no sólo de enero sino de todos los meses y porque las kalendas de todos los meses están bajo la autoridad de Junon, aquel del que ha escrito Várrón, en el libro quinto de Las Cosas Divinas, donde los doce altares corresponden a los doce meses, son consagrados a Junon; Consivio, el sembrador, a causa de la propagación del género humano, que tiene a Jano como autor de su desarrollo; Quirino, como dios de la guerra, a causa de la lanza, llamada curis por los samnitas; Patulcio y Clusivio, porque su templo está abierto, durante la guerra, cerrado durante la paz. He aquí la explicación que se le ha dado a este hecho (Macrobio I, 9, 15-16, la traducción es nuestra).

Otros lo habrían considerado en Roma como uno de los divinos Penates, deidades que protegen el hogar. La tradición veía en él al antiguo rey del país, quien había reinado durante la edad de oro del Lacio. Habiendo acogido a Saturno, aprendió del uránida la agricultura y varias industrias, entre ellas la construcción de barcos y la acuñación de monedas:

... habría sido el primero en emplear barcos para trasladarse de Tesalia a Italia; también sería el inventor de la moneda. En efecto, las monedas romanas de bronce llevaban en el anverso la efigie de Jano y en el reverso una proa de barco (Grimal 1984: 295).

Al ser una deidad totalmente romana, el epíteto avtox $\theta \omega v$ o indígena le fue adjudicado desde la antigüedad:

Regionen istam, quae nunc vocatur Italia, regno Janus obtinuit, qui, ut Hyginus, Protarchum Trallianum secutus, tardit, cum Camese aeque indigena terram hanc ita participata potentia possidebant, ut regio Camesene, oppidum Janiculum vicitaretur.

En el país llamado hoy día Italia, reina Jano, quien, según el testimonio de Higinio, que sigue Protarcho Tralles, reparte el poder sobre nuestra tierra junto con Cameses, indígena como él, el país era llamado Camesino y la villa Janículo (Macrobio I, 7, 19, la traducción es nuestra).

Admitiendo, con Cicerón, que las palabras janus y janua devienen del verbo ire, se ha visto al dios como una manifestación mítica del doble movimiento de la entrada y la salida. 
Macrobio se funda sobre la misma etimología y piensa que Jano simboliza el movimiento eterno del universo. Para otros, Jano sería ya sea Caos, ya sea el mundo, ya sea el cielo luminoso, ya sea el aire. De estas exégesis antiguas, la más racional fue ciertamente la de Nigidio Figulo, citado por Macrobio. Nigidio identifica a Jano con Apolo, a partir del carácter solar:

\begin{abstract}
Janum quidam solem demonstravi volunt et ideo geminum quasi utriusque januae caelestis potentem, qui exoriens aperiat diem, occidens caludat; invocarique primum, cum alicui deo res divina celebratur, ut per eum pateat ad illum cui immolatur accessus, quasi preces supplicum per portas suas ad deos ipsa transmittant. Inde et simulacrum eius plerumque fingitur mano dextera trecentorum et sinistra sexaginta et quinque numerum tenens, ad demonstrandam anni dimensionem, quae praeccipua est solis potestas. Alii mundum, id est caelum, esse voluerunt Janumque ab eundo dictum, quod mundus semper eat, dum in orbem volvitur et ex se initium faciens in se refertur; unde et Cornificius Etymorum libro tertio: "Cicero, inquit, non Janum, sed Eanum nominat, ab eundo." Hinc et Phoenices in sacris imaginem eius exprimentes draconem finxerunt in orbem redactum caudamque suam devorantem, ut appereat mundum et ex ipso ali et in se revolvo. Ideo et apud nos in quattuor partes spectat, ut demonstrat simulacrum eius Faleris advectum. Gavius Bassus, in eo libro quem de dis composuit, Janum bifrontem fingi ait quasi superum atque inferum janitorem, eundem quadriformem quasi universa climata majestate complexum.
\end{abstract}

\begin{abstract}
Algunos pretenden demostrar que Jano es el sol; he aquí el por qué se le dan dos caras, las dos puertas del cielo obedecen a su poder: cuando se levanta, se abre el día; cuando se pone, se cierra. Si se le invoca de primero, cuando se hace un sacrificio sin importar a cuál divinidad, es para que abra el acceso hacia el dios al cual se le ofrece el sacrificio, pues es él quien, por sus puertas, transmite las plegarias de los suplicantes. En consecuencia, también se le representa a menudo sosteniendo en una mano el número 300 y en la otra el número 65, para diseñar la medida del año, que es la principal atribución del sol. Otros han querido ver en él al mundo, es decir, al cielo: Jano vendría de "eundo", porque el mundo va (eat) sin cesar, dando vueltas en círculo y sale de sí mismo para volver sobre sí mismo. He aquí el por qué se encuentrạ en Cornificio, en el libro III de sus Etimologías: "Cicerón escribe, no es Jano sino Eanus, de eundo." Por la misma razón los fenicios, en sus templos, lo han representado como una serpiente enrollada en círculo y devorando su cola, con el objeto de mostrar que el mundo se nutre de su propia sustancia y vuelve hacia sí mismo sin cesar. Entre nosotros, del Falerio. Gavio Basso, en el libro que ha compuesto sobre los dioses, dice que Jano tiene dos caras como portero del cielo y de los infiernos, y también cuatro, como abrazando todos los climas sin excepción en su poder divino (Macrobio I, 9, 9-13, la traducción es nuestra).
\end{abstract}

Las conclusiones de Nigidio han sido adoptadas, en nuestros días, por varios autores, entre ellos Buttman, Schwegler, Preller, Otto Gilbert, quienes concluyen que Jano fue ante todo un dios solar, un antiguo dios itálico de la luminaria celeste. Además, se caracteriza por ser divinidad de las puertas, dios de todo comienzo, deidad de todo origen. Deecke pretende que Jano era, según su propio nombre, el dios de la bóveda celeste, a partir de una génesis etrusca, puesto que fueron ellos quienes inventaron la bóveda arquitectónica y su uso. Para Corssen, dado que el núcleo Janus-Dianus-Divanus deviene de la raíz div (dividir), Jano era el dios de las divisiones del espacio y del tiempo, pero especialmente del tiempo; de esta concepción nace el numen de Jano como dios de la luminaria y del cielo, así como de las puertas. Rosche ha propuesto algo distinto: a partir del epíteto "portero del cielo", relaciona esto con las expresiones "caelum apertum", "caelum clausum", utilizados para designar el cielo sin nubes y el cielo nublado. Señala que las nubes son reunidas y separadas por el viento y concluye que el dios que abre y cierra el ciclo debe ser el viento. Esta teoría suministró ingeniosas relaciones entre Jano 
y el Hermes griego, ambos "rectores viarum", ambos intermediarios entre los dioses y los hombres, ambos tutores de las plazas y las marchas. O también la asimilación entre Jano y Apolo:

\begin{abstract}
Sed physici eum magnis consecrant argumentis divinitatis. Nam sunt qui Janum eundem esse atque Apollinem et Dianam dicant et in hoc uno utrumque exprimi numen affirment. Etenim, sicut Nigidius quoque refert, apud Graecos Apollo collitur qui vocatur, eiusque aras ante fores suas celebrant, ipsum exitus et introitus demonstrantes potentem. Idem Apollo apud illos et 'A $\gamma u$ ULU'S nuncupatur, quasi viis praepositus urbanis: illi enim vias quae intra pomeria sunt àyulás Vappellant; Dianae vero ut Triviae viarum omnium tribuunt potestatem. Sed apud nos Janum omnibus praeesse januis nomem ostendit, quod est simile $\Theta v p a \iota \omega$. Nam. et cum clavi ac virga figuratur, quasi omnium et portarum custos et rector viarum.
\end{abstract}

Pero los sabios establecen su carácter divino sobre sus fuertes pruebas. Hay quienes pretenden que Jano corresponde a la vez a Apolo y a Diana y afirman que él resume en sí mismo a las dos divinidades. En efecto, nos refiere el propio Nigidio, entre los griegos se adora a Apolo bajo el nombre de $\Theta u p a t o s, y$ ellos preparan sus altares delante de sus puertas, para mostrar que la salida y la en-

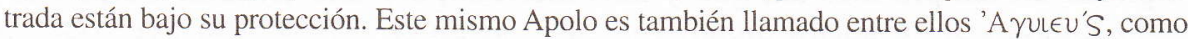
dios tutelar de las calles; llaman, en efecto áyuca, la calles del interior del recinto religioso. En cuanto a Diana, bajo el nombre de Trivia [que preside las encrucijadas], ellos la reconocen como la divinidad de todas las rutas. Entre nosotros, Jano es el dios de las puertas, como lo muestra su nombre, sinónimo de Evpalos. En efecto, se le representa con una llave y una vara, como guardián de todas las puertas y guía de todos los caminos (Macrobio I, 9, 5-7, la traducción es nuestra).

\title{
3. Lugares de culto
}

El más antiguo santuario de Jano, cuya construcción fue atribuida a Numa Pompilio, se hallaba en el extremo superior del Foro y tenía la forma de un arco doble, cuyos dos frentes, anterior y posterior, estaban unidos por un doble muro lateral. Una imagen de este templo nos ha sido conservada en una moneda de Nerón. Los otros santuarios del dios eran de arcos bifrontes (de dos caras) o quadrifrontes (de cuatro caras o aberturas). Se encuentran en los sitios principales de paso: sea en las cercanías de las plazas como el Forum Transitorium, Forum Barium, Forum Olitorum, sea en las encrucijadas formadas por dos caminos, sea en las puertas de la villa.

Es sobre todo en Roma, donde se encuentran las huellas importantes del culto a Jano. Ahora bien, no necesariamente hay que creer que todos los arcos, llamados jani, fueran consagrados al dios, pues sólo algunos eran templos o santuarios. El más antiguo y el más reverenciado era el de Janus Geminus, situado en el extremo superior del Foro, cuya fundación era atribuida al rey Numa. Pese a que no se conserva en la actualidad, gracias a los numerosos detalles registrados en los textos, tenemos noticia de su estructura y una moneda de Nerón nos da una idea general.

Otro santuario igualmente antiguo y venerado era el que estaba situado en el Janículo o cerca de esta colina, pero su existencia nos es desconocida. Más reciente y mejor conocidos son los templos construidos cerca del teatro de Marcelo, cerca del Foro de Nerva o Foror Transitorium. Según Tácito, el santuario, vecino del teatro de Marcelo, había sido erigido por C. Duilio, el vencedor de los cartagineses, durante la primera guerra púnica: 
En este tiempo se dedicaron los templos comenzados por Augusto y arruinados de antigüedad o del fuego; es a saber: de Baco, de Proserpina y de Ceres, junto al Circo Máximo, edificado ya por voto de Aulio Póstumo, dictador; el de Flora, en el mismo lugar, hecho por Lucio y Marco Publicios, entonces ediles, y el de Jano en la plaza de las Hierbas, edificado por Cayo Duilio, el primero que alcanzó gloria naval (Tácito II, 49).

Pero si damos crédito a una curiosa superstición registrada por Festo, el templo había tenido un origen más antiguo: anterior al combate de la Cremera, donde perecen 306 fabios. Tanto Tácito como Festo emplean el término aedes, un Janus quadrifrons. Se ha encontrado uno de estos sitios en Roma, un poco fuera de la antigua Porta Carmentalis del recinto de Servio, cerca del Forum Olitorium, no lejos del Forum Boarium, cerca de la vía en el tránsito entre el Circus Flaminius y el Velabro.

El Janus quadrifrons del Foro de Nerva o Forum Transitorium era, en el siglo tercero del Imperio, el más rico y el más estimado de los santuarios de Jano. Había sido construido para reemplazar un templo más antiguo y más modesto, elevado entre la Curia y la Basilica Aemilia:

... en otras épocas residías es estrecho templo abierto que servía de paso a la inmensa muchedumbre romana (Marcial X, 28).

En el Velabro había dos jani: uno bifrons y otro quadrifrons. El primero, que actualmente es el cuerpo de la Iglesia de San Jorge del Velabro, es de mármol y está coronado de un entablamiento rectilíneo. Fue erigido en el año 204 a.C. cerca del Forum Boarium, en honor a Séptimo Severo y a Julia Domna, por los cambistas y los comerciantes de bueyes (boarii). El Janus quadrifrons, vecino del precedente, es uno de los monumentos mejor conservados de la Roma antigua, su decoración arquitectónica y escultural se mantiene aún intacta. A propósito de este Jano, hay una discusión interesante entre los historiadores: varios autores cuentan que los romanos luego de apoderarse de Falerio, traen de esta villa una estatua de Jano de cuatro rostros, Jani simulacrum cum frontibus quattuor, y esta estatua fue colocada en un templo de cuatro puertas, templum quattuor portarum (Macrobio I, 9, 13). Preller cree que este templo es el Janus quadrifrons erigido en el año 203 a.C. Por el contrario, Roscher afirma que la estatua fue colocada en el Janus quadrifrons del Forum Transitorium, luego de permanercer durante varios siglos en el santuario más pequeño que reemplaza a este Janus quadrifrons. Jordan, por su parte, declara que este monumento, tal como existe hoy día, fue elevado en honor de Constantino, mientras que, según el criterio de Lanciani, sería anterior al reinado del príncipe. Tales opiniones se apoyan en un mismo documento: un graffiti descubierto sobre una de las paredes del arco, donde se lee sin ninguna duda el nombre de Constantino. Lanciani no quiere ver en este graffiti el recuerdo de la visita hecha por Constantino a este monumento.

Festos y Denys de Halicarnaso mencionan un altar de Janus Curiatius, consagrado al mismo tiempo que un altar de Juno Sororia. Este templo se encuentra cerca del Coliseo, cerca de la estatua colosal de Nerón. Sus orígenes se pierden en la antigüedad y fue venerado hasta el quinto siglo de la era cristiana. Plinio habla de una estatua dorada de Jano, traída de Egipto por Augusto y consagrada en un templo. Roscher piensa que esta es una alusión a un nuevo santuario del dios, construido expresamente por Augusto en el Foro que había abierto, el Forum Augusti, santuario mencionado por otros autores, pero algunos, entre ellos Preller, 
aseguran que se trata del aedes Jani, cercano al teatro de Marcelo, cuya restauración fue hecha por Augusto.

\section{El dios de las puertas}

Jano no sólo presidía las puertas públicas, sino también las puertas de las casas, las puertas privadas. Según Cicerón, es a partir del nombre de Jano que las puertas de las casas llevan su nombre respectivo (janua). Roscher muestra con razón que la concepción de Jano como dios de la puerta es análoga tanto desde el punto de vista religioso como desde el punto de vista verbal.

La puerta en sí a menudo no simboliza únicamente la entrada, sino también el espacio que se esconde tras de ella. Como paso a un espacio en sentido metafórico implica "una entrada", por ejemplo, en los templos, las entradas a los aposentos sagrados del "santísimo" suelen caracterizarse por puertas suntuosas que solamente traspasan los grandes sacerdotes consagrados. En múltiples culturas, los ritos sobre el paso de un grado de vida al siguiente (rites de passage) se realizan por medio de una puerta.

Es el tránsito entre dos estados, entre dos mundos, entre lo conocido y lo desconocido, la luz y las tinieblas, el tesoro y la necesidad. La puerta se abre a un misterio, es la apertura que permite entrar y salir, por lo tanto, el pasaje de un dominio a otro. Otra figuración de la puerta es la torana, la boca del monstruo, que evidencia el paso de la vida a la muerte, pero también de la muerte a la liberación: la doble corriente cíclica, expansión y reintegración. La manifestación cósmica se expresa, en China, con la puerta: el trigrama k'uen (principio pasivo, tierra) es la puerta cerrada; el trigrama k'ien (principio activo, cielo) es la puerta que se abre. La apertura y el cierre alternativos implican el ritmo del universo.

La puerta también tiene una connotación escatológica, como lugar de paso, y particularmente de llegada, se convierte en el símbolo de la inminencia del acceso y de la posibilidad de acceso a una realidad superior (de la efusión de dones celestiales sobre la tierra). Por ejemplo, el Cristo del Apocalipsis:

Mira que estoy a la puerta y llamo. Si alguien oye mi voz y abre la puerta, entraré en su casa y cenaré con él y él conmigo (Apocalipsis 3, 20).

Psicoanalíticamente es símbolo femenino que implica todo agujero, dado que permite el paso, el acceso; es pues una imagen de la vagina, asimismo una imagen de los orígenes, del inicio, que como veremos es uno de los ámbitos tutelares de Jano. Un ritual curioso es el de la novia que debe untar los pilares con grasa o aceite antes de entrar a su nueva casa. Jano, como dios de las puertas, era el dios de todos los cambios, de todos los períodos, de todas las alternativas; está presente cuando la materia primordial es separada e individualizada, es también el creador y dios de la puerta de la muerte, principal para la resurrección o el renacimiento.

La puerta manifiesta protección, amparo contra el peligro; la Biblia presenta muchos ejemplos de cómo la puerta debe ser fortificada por emblemas mágicos para defender a la gente de poderes sobrenaturales: la sangre puesta en los quicios de las casas hebreas para salvaguardarlos de los ángeles destructores de Dios, quienes mataban a los primogénitos en Egipto. 
Jano es también la deidad de los goznes (cardines), dios del umbral (limes), divinidad de las hojas de puerta (fores). La significación esotérica del umbral proviene de su papel de tránsito entre lo exterior (lo profano) y lo interior (lo sagrado). Implica tanto la separación como la posibilidad de alianza, de unión, de reconciliación. Mantenerse en el umbral es evidenciar el deseo de adherirse a la preceptiva de la morada o templo, mientras que expulsar a alguien del umbral es renegar de él y rechazar su adhesión. Ciertamente, el umbral es la frontera de lo sagrado, que participa de la trascendencia del centro. En muchas culturas, se le considera habitado por un espíritu protector propio, el "guardián del umbral". La costumbre de alzar a la novia antes de ingresar al hogar conyugal quizás acontece para hacer creer al guardián que ya anteriormente formaba parte de los habitantes de la vivienda. El guardián del umbral tiene el poder de mantener alejados a los intrusos indeseados o a los seres demoníacos. En Europa se acostumbraba grabar un pentagrama o estrella de cinco puntas en la madera del umbral.

En el libro de Ezequiel, una fuente sagrada surge del umbral:

Y me hizo volver hacia la puerta de la casa del Señor; y vi que brotaban aguas debajo del umbral de la casa hacia el Oriente, pues la fachada de la casa miraba al Oriente, y las aguas descendían hacia el lado derecho del templo, al Mediodía del altar... (Ezequiel 47,1)

El poder de muerte es ilustrado en 1 Reyes 14, 17, donde el hijo de Jeroboam (según la profecía) murió cuando su madre cruzó el umbral.

La concepción de Jano como dios de la puerta en general debería ser precisada. Jano presidía esencialmente la puerta y todo lo concerniente a ella en lo material (pilares, dintel, goznes, etc.) y en lo funcional (la entrada y la salida) (Cicerón II, 27, 67). Él protege las salidas y los retornos, es el dios de las carreteras por las cuales se partía y por las cuales se regresaba.

Et quia Janum cum Saturno regnasse commemoravimus, de Saturno autem quid mythici, quid physici aestiment, iam relatum est. de Jano quoque quid ab utrisque iactetur in medium proferemus. Mythici referunt regnate Jano omnium domos religione ac sanctitate fuisse munitas idcircoque ei divinos honores esse decretos et ob merita introitus et exitus aedium eidem consecratos. Xenon quoque primo Italicon tradit Janum in Italia primum dis templa fecisse perpetuam. Quidam ideo eum dici bifrontem putant quod et praeterita sciverit et futura providerit.

Tras haberse acordado que Jano y Saturno reinaran conjuntamente hemos recordado lo que piensan de Saturno las mitologías y los sabios; lo que unos y otros dicen igualmente de Jano, nosotros ahora lo vamos a exponer. Las mitologías narran que, bajo su reinado, la religión y la virtud protegen cada casa y que, por esta razón, se le otorgan los honores divinos; por otro, a causa de sus méritos, la entrada y la salida de las casas le fueron consagradas. Xenón añade, en el primer libro de su Historia de Italia, que Jano fue, en Italia, el primero al que le elevaron templos entre los dioses y le fijaron los ritos en sacrificio; esto le valió, en estas ceremonias, ser invocado como el primero. Algunos piensan que se le llama Bifrons (de dos caras), porque él sabía el pasado y preveía el porvenir (Macrobio I, 9, 1-4, la traducción es nuestra).

Así las cosas, Jano es dios tutelar de las puertas y de todos los movimientos que de ella se derivan. Por ello posee como atributos la llave (clavis), con la cual abre y cierra, y el bastón (baculum, virga), con la cual los porteros (janitores) separan todo lo que no debe penetrar en la casa. La llave está a tenor con la dualidad de Jano: su doble rol de apertura y de cierre, une y desune. Las llaves de Jano abren también las puertas solsticiales, es decir, el acceso a las fases 
ascendente y descendente del ciclo anual, que encuentran su equilibrio en los equinoccios. El dios estaba considerado como guía de las almas, de ahí su doble cara, la una vuelta hacia la tierra y la otra hacia el cielo, con su bastón en la mano derecha y su llave en la mano izquierda.

Janus bifrons o geminus es su representación evidente. Macrobio nos explica:

Post ad Janum solum regnum redactum est, qui creditur geminam faciem practulisse, ut quae ante quaeque post tergum essent intueretur; quod procul dubio ad prudentiam regis sollertiamque referendum est, qui et praeterita nosset et futura prospiceret...

En consecuencia, Jano posee sólo el poder real. Se cree que tenía dos caras, las cuales le permitían ver hacia adelante y hacia atrás, esto sin ninguna duda debe aplicarse a la sabiduría y a la habilidad de este rey, quien conocía el pasado y preveía el porvenir... (Macrobio I, 7, 20, la traducción es nuestra)

Deidad de las entradas y de las salidas, debía vigilar al mismo tiempo el exterior y el interior de la casa; dios de los jani, debía tener los ojos fijos de uno y otro lado del arco. En el antiguo santuario, erigido por Numa Pompilio, en el extremo superior del Foro, las dos caras de la estatua de Jano ven hacia el Oriente y el Occidente respectivamente.

La influencia atribuida a Jano sobre las puertás, sobre las entradas y las salidas, sobre las salidas y los retornos, explica el mismo papel importante que este dios y su templo del Foro juegan durante largo tiempo en el Estado romano. Las puertas del santuario debían estar y permanecer abiertas durante las guerras que Roma sostenía; las puertas no podían estar cerradas hasta que se restableciera completamente la paz. Varrón hace remontar esta costumbre hasta el rey Numa Pompilio y tal proceder subsistió aún en el siglo IV d.C. Durante este período de once siglos, las puertas del templo de Jano raramente fueron cerradas y cuando se hacía era por cortos lapsos: bajo el reinado de Numa, en el 235 a.C; tres veces bajo el imperio de Augusto, en el 29 a.C., en el 25 a.C. y en el mismo año del nacimiento de Cristo; luego bajo el mandato de Nerón, de Marco Aurelio, de Cómodo, de Gordiano III y en el siglo IV.

Los antiguos mismos y los historiadores modernos se han esforzado en explicar esta costumbre curiosa, propia de los romanos. Varias explicaciones han sido propuestas. Unas han pretendido hallar el origen en una antigua leyenda local, que han recogido Ovidio y Macrobio:

Cum bello Sabino, quod virginum raptarum gratia commissum est, Romani portam quae sub radicibus collis Viminalis erat, quae postae ex eventu Janualis vovata est, claudere festinarent, quia in ipsam hostes ruebant, postquam est clausa, mox sponte patefacta est, cumque iterum ac tertio idem contigisset, arnati plurimi pro limine, quia claudere nequibant, custodes steterunt, cumque ex alia parte acerrimo proelio certaretur, subito fama pertulit fusos a Tatio nostros. Quam ob causam Romani qui aditum tuebantur territi profugerunt; cumque Sabini per portam patentem irrupturi essent, fertur ex aede jani per hanc portam magnam vim torrentium undis scatentibus erupisse multasque perduellim catervas aut exustas ferventi aut devoratas rapida voragine deperisse. Ea re placitum ut belli tempore velut ad urbis auxilium profecto deo fores rescrarentur. Haec de Jano.

Durante la guerra contra los sabinos, provocada por el rapto de vírgenes, los romanos quisieron cerrar de prisa la puerta que estaba al pie del Viminal y, más tarde, el acontecimiento se hizo 
llamar Janualis, puerta atacada por el enemigo. Cerrada, se vuelve a abrir pronto ella misma. Como el mismo fenómeno era producido una segunda y una tercera vez, y los romanos no podían cerrarla, permanecían en armas y en gran número para guardar. Sin embargo, un combate encarnizado se libra del otro lado, y, de pronto, el ruido se propaga (tanto) que nuestros soldados habían sido puestos en la derrota por Fabio. Por esta noticia, los romanos que defendían lá entrada se fugaron espantados. Pero, cuando los sabinos iban a precipitarse por la puerta grande abierta, se cuenta que, del templo de Jano salían los torrentes de agua que brotan con gran fuerza y que se precipitan por esta puerta, si bien los numerosos grupos enemigos perecen quemados por el agua que estaba hirviendo, o tragados por sus remolinos torrenciales. Por razón de este acontecimiento, fue decidido que, en tiempos de guerra, las puertas (del templo de Jano) serían abiertas, como para dar acceso a este dios que venía a brindar socorro a nuestra villa. He aquí a Jano (Macrobio I, 9, 17-18, la traducción es nuestra).

Según esta leyenda, en el momento en que los sabinos, conducidos por Tacio, iban a forzar la puerta de Roma, situada al pie del Viminal y más tarde llamada Porta Janualis, Jano mismo habría hecho salir de repente una fuente de agua hirviendo contra los agresores y así se habría salvado Roma. Desde entonces el templo de Jano permanecería abierto durante todas las guerras de los romanos, con el fin de que el dios pudiera ofrecer, sin obstáculo, el socorro para su pueblo, como lo había hecho en los primeros tiempos de la ciudad. Para otros, era en el santuario de Jano donde residía el genio de la guerra; en tanto duraran las hostilidades era necesario dejar libre a la deidad, con el objeto de que se lanzara contra los enemigos de Roma. La paz general restablecida, se encerraba de nuevo en el santuario. Esta explicación

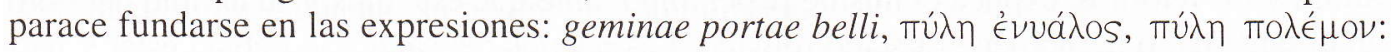

Hay dos puertas de la guerra (así son llamadas), religiosamente respetadas por el miedo que infunde el fiero Marte... (Virgilio, 1961: VII, 607)

Tiene en Roma un templo, también con dos puertas, a las que llaman puertas de la guerra, porque es de ley que estén abiertas cuando hay guerra y que se cierren hecha la paz; cosa difícil y pocas veces vista, habiendo tenido siempre el gobierno que atender a alguna guerra para contener a las naciones bárbaras que por todas partes lo rodeaban. Sólo se cerró bajo el imperio de César Augusto, después de la derrota de Antonio, y antes en el consulado de Marco Atilio y Tito Manlio, por poco tiempo, porque al punto sobrevino la guerra y fue preciso abrirlo. Mas bajo el reinado de Numa, ni un día siquiera se vio abierto, sino que por cuarenta y tres años continuamente se mantuvo cerrado... (Plutarco, Numa, XX)

Una explicación del mismo género, pero a la inversa, por así decir, es aquella según la cual el Janus geminus del Foro habría sido la morada, no de un genio de la guerra, sino del genio de la paz. Cuando la guerra había terminado en todas partes, se cerraban las puertas del templo para conservar la paz el mayor tiempo posible, pero cuando una nueva guerra estalla, se abrían esas puertas y el genio de la paz abandonaba Roma. Por ello, Horacio llama a Jano custos pacis y Ovidio lo expresa así:

Pero ¿por qué estás oculto en tiempos de paz, y en cambio abres tus puertas cuando se declara una guerra? Sin tardanza alguna dio contestación a mi pregunta. Mi puerta, quitado el cerrojo, se abre de par en par para que el pueblo, que ha partido a la guerra, tenga también abierta la vía del retorno. En tiempos de paz mantengo cerradas las puertas para que la paz no pueda escaparse. Por la divina voluntad del César voy a estar largo tiempo cerrado. Así dijo, y levantando sus ojos que miran en opuestas direcciones, contempló cuanto encierra el mundo entero. 
Reinaba la paz, y el Rin, motivo de vuestro triunfo, Germánico, te había rendido sus aguas finalmente sometidas. Jano, ¡haz que la paz y los ministros de la paz sean eternos, y concédenos que el artífice de esta paz no abandone su obra! (Ovidio, Fastos I, 277-88)

... las puertas cerradas del templo de Jano, guardián de la paz... (Horacio, Epíst. II, 255)

Entre los estudiosos modernos se destaca Preller, quien retiene un pasaje de Servio y piensa que en este caso Jano era considerado sobre todo como rector viarum, como el dios que preside las salidas y los retornos. Cuando los romanos se encontraban fuera de Roma, en los caminos, era indispensable que Jano pudiera abandonar libremente su santuario, para salir a salvar a aquellos que imploraran o necesitaran de su protección. Cuando todos los ciudadanos habían ingresado en sus hogares, el dios no tenía que intervenir fuera de Roma, las puertas de su templo podían entonces estar cerradas. Roscher parte del hecho de que las deidades fueran reverenciadas y sus cultos se celebraran en el Foro, lo cual constituía el modelo para los dioses y sus cultos domésticos: el templo de Vesta es el lugar común de toda la ciudad; el Janus geminus está en el Foro así como la janua está en cada una de las casas particulares: era, de cualquier manera, la puerta ideal de la urbe. Considerábase de muy mal augurio que la puerta fuese cerrada detrás de la salida de los ciudadanos que habían dejado Roma para ir a combatir a los enemigos; por el contrario, era necesario que el acceso a su Foro estuviera abierto constantemente. Roscher compara y asimila a la ciudad con el hogar, llama a los porteros de la casa $j u$ nitores, quienes tenían el hábito de mantener abierta la puerta del hogar, cuando los miembros de la familia habían salido, con el objeto de que no tengan la necesidad, a la hora de entrar, de llamar a alguien. Al contrario, cuando el pater familias y los suyos estaban en la casa, la puerta del hogar permanecía cerrada, a fin de que los intrusos no pudieran ingresar de improviso.

Estas diversas explicaciones tienen un punto en común: Jano es el dios de las puertas, protege la entrada y la salida, la salida y el retorno. Pero gracias al papel que ha jugado en la vida militar de Roma y a la solemnidad con que las puertas de su templo eran abiertas, cuando se presentaba la ocasión, pasó por los ojos de los romanos como dios de la guerra. El sobrenombre Quirino le fue otorgado por lo anterior. El numen de Jano, portarum custos et rector viarum, se entendió pronto. No sólo presidía las puertas privadas o públicas sino las rutas en general, en fin todos los accesos. Adorado como guardián de las puertas, fue llamado Portunus y, bajo este apelativo, poseía un templo en las orillas del río Tíber, junto al puente Aemilius. Se le atribuía la invención del transporte en barca: muchas antiguas monedas ostentaban en el anverso a Jano bifronte y en el reverso una proa de barco. Fue invocado como jefe de las rutas por las cuales las oraciones humanas subían hasta los dioses, es decir, un intermediario entre los hombres y lo divino.

\section{Dios de los inicios}

Jano era también en Roma el dios de los comienzos y esta concepción no era ni menos popular ni menos importante que la precedente. Al inicio de cada día, era invocado como dios de la mañana (matutinus pater): 
¡Oh padre de la mañana, o Jano si prefieres que así te llame...!(Horacio, Sátiras II, 620)

Asimismo el primer día de cada mes (las kalendas) le estaba especialmente consagrado y como también le eran atribuidas a Junon, Jano era llamado Junonio. Además, presidía el primer mes del año solar, mes durante el cual los días se reiniciaban para crecer (Januarius). Las kalendas de enero estaban consideradas entre las fiestas más populares de Roma, no había persona que no las celebrara. Muchos documentos prueban que Jano es el retorno del año, la llegada del nuevo año. En una moneda de Cómodo, este emperador está representando a Jano: es bifrons y lleva un báculo (virga) en la mano izquierda y en la derecha sostiene una especie de arco, el cual presenta las cuatro estaciones. A la derecha de la moneda aparece un niño desnudo en un campo, quien porta el cuerno de la abundancia: el año nuevo. En la estatua de Jano, que adorna el templo del Foro, los dedos estaban dispuestos de tal manera que se leía la cifra 365, número de los días del año.

Esta deidad de los jani había llegado a ser dios de la puertas y de todos los accesos, pero también se le invocaba al inicio del día, del mes y del año, considerándosele dios de todos los comienzos, de todos los inicios. Fue llamado, de forma general, el padre del tiempo, temporis et aevi deus, temporis auctor, annorum sator, fastorum genitor, ảpxì tov xpóvou.

Padre magnífico de los años y del espléndido mundo... (Marcial X, 28,1)

Jano, padre de nuestros fastos... (Marcial VIII, 2,1)

Pasa por presidir el inicio de todo trabajo, de toda empresa, de toda acción: fue

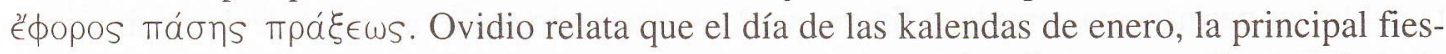
ta del dios, cada romano pone en función su trabajo habitual del año, para colocarse bajo la protección de Jano:

\begin{abstract}
Después de estas palabras me preguntaba yo admirado la razón por la que el primer día del año no estaba libre de procesos jurídicos. Escucha el motivo -dijo Jano. El año que se inicia lo he ligado a los trabajos que deben realizarse, con el fin de que el año entero no sea perezoso por un auspicio de pereza. Por esto mismo cada uno estrena su oficio realizando algo, y simplemente testimonia cuál es su trabajo habitual. A continuación pregunté: ¿Por qué cuando trato de propiciarme a cualquiera otra de las divinidades es a ti, Jano, a quien primero ofrezco el incienso y el vino? Es -me dice- para que a través de mí, que guardo los umbrales, puedas tener acceso a los dioses a los que te diriges. Pero ¿por qué en tus kalendas se pronuncian palabras felices, y expresamos y recibimos mutuamente buenos deseos? Entonces el dios, apoyándose en el bastón que llevaba en su mano, me responde: los presagios suelen encontrarse en los comienzos. Es a la primera palabra a la que volvéis vuestros tímidos oídos, y es el ave vista en primer lugar la consulta del augur. Este primer día los templos y los oídos de los dioses están abiertos; ninguna lengua pronuncia palabras inútiles, y las palabras tienen todo su peso (Ovidio, Fastos I, 165 y ss).
\end{abstract}

Con solo el inicio, se asegura el éxito de todo trabajo, durante todo el año. Esto fue sin duda el origen de la antigua costumbre, en la cual se atribuye a Jano la invención del lenguaje, de la agricultura, de la organización social y política, la arquitectura en función de los templos y las casas, el transporte en barca y la acuñación de monedas. El origen de la mayor parte de la práctica de la actividad humana le fue referido. 
El propio origen de la vida le fue consagrado. Ciertas familias patricias lo adoraban como su padre o genius de la gens. Los patricios le rendían culto particular, bajo el nombre de Janus Patricius. Preller supone que este Jano era para las familias patricias de Roma un dios nacional, como Apolo tratpwos lo fue para los jonios de Atenas. Lo que corrobora esta hipó-

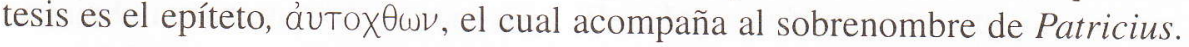

Puesto que Jano era el dios de los comienzos, se le invocaba siempre de primero en las oraciones y en las ceremonias religiosas. En la lista de los dioses ocupaba el primer lugar: Jano, Júpiter, Marte, Quirino, Vesta. Así era citado por los grandes sacerdotes de la religión romana.

Jano era entonces en Roma tanto deidad de las puertas y de las entradas, como divinidad de los inicios. Estos dos conceptos se mezclan, no sin que el lenguaje y la literatura hubieran contribuido a su aproximación. Jano era el portero del cielo, que abre al sol y levanta los caminos celestes, los cuales se cierran detrás del crepúsculo. Abre la puerta del año: anni januam pandit. Algunas expresiones muestran la presencia de una confusión a propósito de Janus Consivius. Roscher señala, con justa razón, que el sustantivo initium significa etimológicamente "entrada" (in, ire). Así no es de extrañar que las dos concepciones de Jano se hayan aproximado y confundido poco a poco. Igualmente es una causa verbal que se relacione a Jano con las fuentes, con la ninfa Juturna, con Fons y con Tíber. El dios que abre y cierra, Patulcius y Clusius podía abrir y cerrar las fuentes y los arroyos, según las expresiones corrientes: aperire fontes, claudere fontes.

La idea de Jano como dios de todos los comienzos engendra lógicamente una concepción mucho más abstracta. Vemos a un Jano que preside el inicio, el nacimiento mismo del mundo, una especie de creador, de demiurgo, dominador del universo, preceptor de los movimientos universales. Ovidio habla en estos términos:

A mí [Jano] me llamaban Caos los antiguos - pues yo soy cosa antigua- (...) Este aire puro, y los tres elementos restantes -el fuego, el agua y la tierra-formaban un solo confuso montón. Pero tan pronto como esta masa se desmembró por el conflicto de sus componentes, y segmentada, marchó hacia moradas nuevas, el fuego tendió hacia las alturas, el aire ocupó el lugar más cercano, y la tierra y el mar se asentaron en el centro. Fue entonces cuando yo, que era una bola y una masa informe, tomé aspecto y unos miembros dignos de un dios (Ovidio, Fastos I, 117 y ss).

Un contemporáneo de Cicerón, M. Messala, define así a Jano, en un fragmento conservado por Macrobio:

Saliorum quoque antiquissimi carminibus deorum deus canitur. M. etiam essala, Cn. Domitii in consulatu collega, idemque per annos quinquaginta et quinque augur, de Jano ita incipit: Qui cuncta fingit eademque regit, aquae terraque vim ac naturam gravem atque pronam in profundam dilabetem, ignis atque animae levem in inmensum sublime fugientem, copulavit circumdato caelo; que vis caeli maxima duas vis dispares colligavit.

Los cantos salios, los más antiguos, lo llaman también el dios de dioses. M. Messala igualmente, aquel que fue, en el consulado, colega de Cn. Domicio, quien durante 55 años desempeñó funciones de augur, comienza así a hablar de Jano: Aquel que crea todas las cosas y, al mismo tiempo, las gobierna, aquel que ha unido, en los alrededores del cielo, por una parte, la esencia y la naturaleza del agua y de la tierra, (entes) pesados y que tienden siempre a descender, por otra parte, aquellas del fuego y del aire, cuerpos ligeros y que escapan hacia la inmensidad de lo alto; ésta es la poderosa fuerza del cielo que ha unido estas fuerzas contrarias (Macrobio I, 9, 14). 


\section{Ceremonias rituales}

Las ceremonias del culto de Jano se celebraban al comienzo del mes, el día de las kalendas, habiendo sido las más populares las de enero. En el primer día del año, los romanos no sólo renuevan los votos sino que intercambian regalos. El 7 de enero había juegos en el circo, dos días más tarde, el 9 de enero, durante la fiesta agnalia, un morueco (princeps gregis) era sacrificado en honor a Jano; el 17 de agosto y el 18 de octubre había ceremonias particulares en el santuario del dios, cerca del teatro de Marcelo. La ofrenda habitual, la cual se deposita al inicio de cada mes en los altares, era una especie de pastel especial para el culto, llamado strues, janual o popanon. Se le consagra también trigo, vino y una oveja en la fiesta agnalia.

No había en Roma, un colegio de sacerdotes ni sacerdotes propios de Jano. Los salios lo nombran en sus cantos rituales y el Rex sacrorum celebra, en casos particulares, ceremonias cultuales de Jano y lo nombra de primero en la lista de los dioses para cualquier ritual. Por tanto, el Rex sacrorum era considerado como el sacerdote de Jano, sin serlo en realidad.

Fuera de Roma, las huellas del culto son poco numerosas en Italia y en las provincias. En Italia, Jano tenía un santuario y una estuatua quadrifrons en Falero; era adorado en Etruria; una inscripción votiva en su honor ha sido descubierta en Albano. Las monedas de varias villas de Italia, de Sicilia y de Grecia, por ejemplo de Volaterra y Telamón en Etruria, de Siracusa y de Palermo en Sicilia, nos parecen pruebas poco convincentes de la popularidad del dios, además la doble cara no demuestra que sea la efigie de Jano, puede ser una imagen de Hermes, sobre todo cuando el dios es representado joven, imberbe y ataviado con una cofia puntiaguda.

En las provincias del imperio romano estatuas dedicadas a Janus pater, Janus Augustus, Janus Geminus han sido encontradas en Dalmacia, en Noruega, en África proconsular, en Numidia y en Galia meridional. Es verosímil que el culto de Jano fuera llevado a diversos sitios del Imperio por soldados y colonos.

\section{Los jani}

En Roma se llaman jani a todas las puertas abovedadas o construidas en forma de arco, que sirven de pasaje. Los jani, que Cicerón define como transitores previae, se encontraron antiguamente en el Foro o cerca de él. Se conocen tres; la entrada de uno de ellos es llamada janus medius. Era ad janum medium que se trataban los asuntos de bolsa y el janus medius se elevaba en la cercanía del templo de Cástor, hacia el extremo inferior del Foro. No se sabe dónde se encontraban los otros jani. Jordan niega la atribución de un sentido topográfico preciso a las expresiones janus summus y janus imus, empleadas por ciertos autores. Combate la opinión de quienes afirman que las advocaciones summus, medius e imus correspondan a los jani ubicados supuestamente en las partes superior, media e inferior del Foro, respectivamente.

Los jani parecen haber tenido una importancia particular como parte integral de un lugar público de reunión. Fuera de Roma y en general fuera de las villas, los jani habían sido construidos sobre los grandes caminos romànos. Los más conocidos fueron erigidos por Augusto en la frontera de Bética. 


\section{Bibliografía}

Biedermann, Hans. 1993. Diccionario de símbolos. Barcelona: Paidós.

Cicerón. 1984. Sobre la naturaleza de los dioses. Barcelona: Sarpe.

Cirlot, Eduardo. 1985. Diccionario de símbolos. Barcelona: Labor.

Chevalier, Jean. 1988. Diccionario de símbolos. Barcelona: Herder.

Grimal, Pierre. 1988. Diccionario de mitología griega y romana. Barcelona: Paidós.

Horacio. 1986. Obras completas. México: Porrúa.

Las religiones antiguas. 1984. Vol. III. México: Siglo XXI.

Marcial. 1976. Epigramas. Barcelona: Iberia.

Ovidio. 1984. Fastos. Madrid: Editora Nacional.

Plutarco. 1973. Vidas paralelas. Madrid: Aguilar.

Sagrada Biblia. 1958. New York: Grolier.

Suetonio. 1978. La vida de los doce Césares. México: Grolier.

Tácito. 1984. Anales. Navarra: Txertoa.

Virgilio. 1961. La Eneida. México: Editora Nacional.

Vries, Ad de. 1984. Dictionary of Symbols and Imagery. Netherlands: Elsevier. 